\title{
EMI/EMC: princípios gerais, considerações para sistemas de potência e aplicações com foco em subestações
}

\author{
EMI/EMC: general principles, considerations for power systems and applications focusing on \\ substations

\section{José Eduardo Henriques da Silva*, Carlos Jesivan Marques Albuquerque, Rodrigo de Souza Campista Ferraz, José Antônio Bento de Andrade}

\begin{abstract}
Resumo
A crescente demanda de energia elétrica em tempos modernos exige sistemas de potência crescentemente confiáveis, em todos os segmentos envolvidos na geração, transmissão e distribuição. Neste sentido, perturbações eletromagnéticas, de origem externa - como as descargas atmosféricas e as oriundas de subsistemas vizinhos, bem como as originadas internamente nos equipamentos, representam constante preocupação. Subestações, em particular, que na atualidade apresentam equipamentos cada vez mais complexos em suas funções, e dependentes de dispositivos mais sensíveis a tais perturbações, exigem crescentes cuidados na obtenção de ambiente eletromagnético não prejudicial ao seu desempenho. Este artigo trata da interferência eletromagnética (EMI) e do processo de Compatibilidade Eletromagnética (EMC), questões muito presentes em sistemas de potência.
\end{abstract}

Albuquerque CJM, Ferraz RSC, Andrade JAB. EMI/EMC: princípios gerais, considerações para sistemas de potência e aplicações com foco em subestações. Revista Eletrônica Teccen. 2016 Jan./Jun.; 09 (1): 57-65.

Palavras-Chave: EMI/EMC; Sistemas de Potência; Subestações de Energia.

\begin{abstract}
The growing demand for electricity in modern times requires increasingly reliable power systems in all segments involved in the generation, transmission and distribution. In this regard, electromagnetic disturbances of external origin - as atmospheric discharges and those from neighboring subsystems, as well as the equipment originated internally, are sources of constant concern. Substations in particular, have increasingly complex equipment and are dependent on more sensitive devices which are subject to electromagnetic disturbances thus requiring greater care in achieving an electromagnetic environment consistent with its performance requirements. This paper deals with the electromagnetic interference (EMI) and the process of Electromagnetic Compatibility (EMC), very present issues in power systems.

Keywords: EMI/EMC; Power Systems; Power Substations.
\end{abstract}

\section{Introdução}

A interferência eletromagnética (EMI) está presente tanto no cotidiano das pessoas comuns como, principalmente, em ambientes que operam com altas tensões e altas correntes, como indústrias subestações, etc.

No dia a dia a EMI pode ser percebida quando você está assistindo televisão e passa um avião. A imagem da televisão sofre distorções, ruídos e chiados. Esta degradação não tem consequências graves se não o desconforto visual e auditivo, entretanto, no caso de um ambiente industrial, uma interferência eletromagnética pode somar sinais a um Controlador Lógico Programável (CLP) que pode acionar uma prensa ou uma esteira e causar danos mais graves.

A EMI é justamente a degradação na performance de um dispositivo, equipamento ou sistema, causada por distúrbios eletromagnéticos. A compatibilidade eletromagnética (EMC) é a solução para a problemática da EMI, que nada mais é do que a aptidão apresentada por um dispositivo, equipamento ou sistema de operar satisfatoriamente em um meio eletromagnético sem ser interferido e sem introduzir indesejáveis distúrbios neste ambiente.

A EMI é consequente da ação das perturbações eletromagnéticas. Essas perturbações têm diversas origens e meios específicos para se propagarem e ocasionaremmau funcionamento emalgumequipamento ou sistema, como exemplifica a Figura 1.

\section{Fundamentos}

a) Campo elétrico: é um campo vetorial, constituído por uma distribuição de vetores, um para cada ponto de uma região em torno de um objeto eletricamente carregado; b) Campo magnético: é a região do espaço onde são observáveis efeitos magnéticos produzidos por uma fonte magnética;

c) Distúrbio eletromagnético: é o fenômeno eletromag-

Afiliação dos autores: Universidade Severino Sombra, Vassouras-RJ, Brasil.

* Endereço para correspondência: Universidade Severino Sombra, Av. Exped. Oswaldo de Almeida Ramos, 280 - Centro - Vassouras, RJ - CEP $27700-000$.

E-mail: jeduaardo.tg@gmail.com 

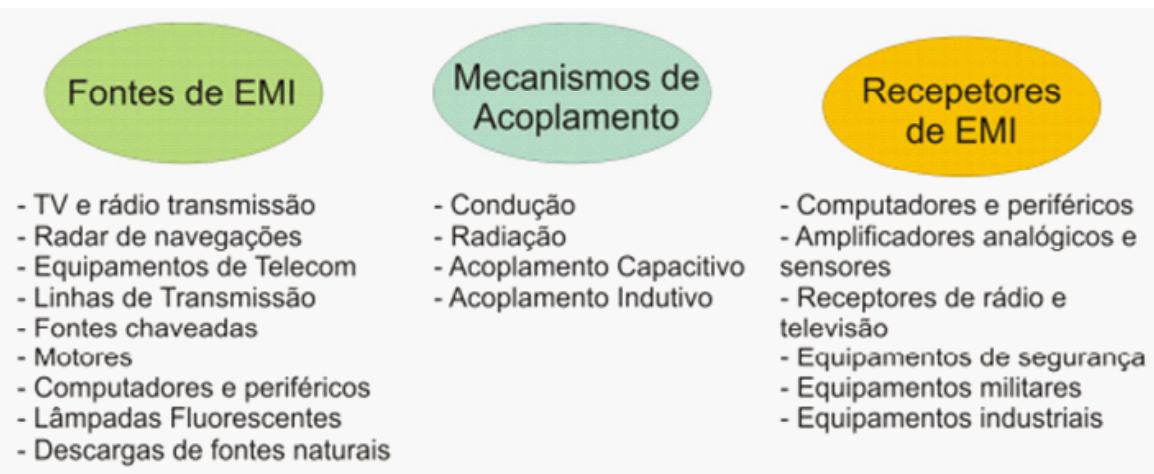

Figura 1. Fontes, mecanismos de acoplamento e receptores de EMI. Fonte: BELTRAME, 2010 .

nético que pode degradar a performance de um dispositivo, equipamento ou sistema;

d) Lei de Lenz: Enuncia que o sentido da corrente induzida é o oposto da variação do campo magnético que lhe deu origem;

e) Lei de Faraday: Enuncia que campos magnéticos variáveis no tempo induzem f.e.m (força eletromotriz) sobre condutores nele envolvidos.

\section{Perturbações Eletromagnéticas}

AIEC(International Electrotechnical Comission) define as perturbações eletromagnéticas como fenômenos eletromagnéticos que diminuem ou impedem o funcionamento correto de um equipamento ou sistema. Essas perturbações provêm ou se caracterizam como fenômenos de diferentes tipos, como as que se seguem: a) Harmônicas: frequências múltiplas inteiras da frequência nominal da rede de alimentação;

b) Inter-harmônicas: frequências não múltiplas inteiras da frequência nominal da rede de alimentação; c) Flutuação de tensão: aumento da tensão nominal em até $10 \%$;

d) Queda de tensão: redução da tensão nominal em até $10 \%$;

e) Interrupção momentânea: interrupção no fornecimento de energia elétrica por um período que permanece entre 0,5 e 1 ciclo, podendo chegar a 1 minuto;

f) Desequilíbrio da tensão trifásica: diferença na amplitude de uma ou mais fases de um sistema de alimentação trifásico;

g) Variação da frequência de alimentação: variação do valor de frequência em torno do valor nominal.

\section{Acoplamentos}

Os acoplamentos são a maneira pela qual uma perturbação eletromagnética se conecta, desde a fonte até o receptor. Os acoplamentos podem ocorrer de 4 maneiras distintas: acoplamento por radiação, acoplamento indutivo, acoplamento por condução e acoplamento capacitivo, conforme ilustra a Figura 2.

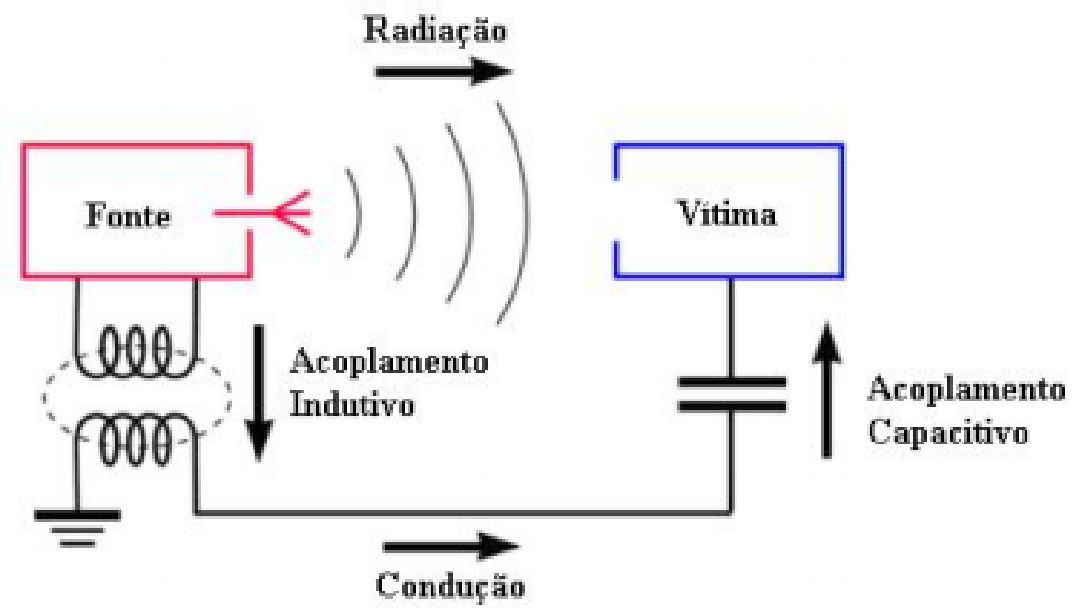

Figura 2. Métodos de Acoplamento. Fonte: BELTRAME, 2010. 


\section{Acoplamento Indutivo}

Ocorre quando não existe ligação física entre a fonte e a vítima e ocorre por meio da indução de correntes e tensões através do campo magnético, conforme enuncia a Lei de Faraday. Sua representação é dada por meio de indutores. Na Figura 3, o campo magnético do condutor 1 induz tensões e correntes no condutor 2, provocando a tensão $V_{\text {ruido }}$.

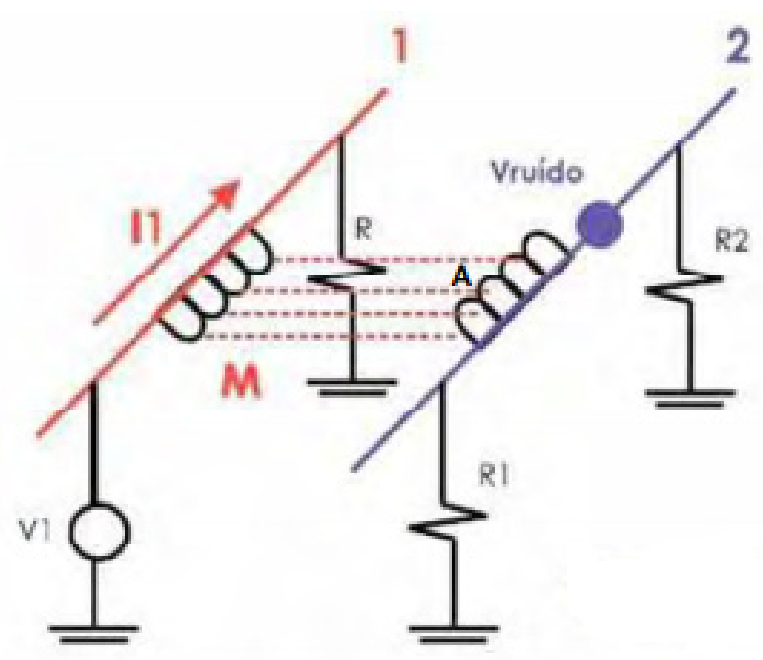

Figura 3. Acoplamento Indutivo. Fonte: SARTIN, 2010.

\section{Acoplamento Capacitivo}

Ocorre quando não existe ligação física entre fonte e vítima e ocorre por meio das capacitâncias parasitas existentes entre elas, isto é, quando existe diferença de potencial entre dois condutores e um dielétrico entre eles, caracteriza-se, por definição, um capacitor. $\mathrm{Na}$ prática o dielétrico pode ser o próprio ar. $\mathrm{O}$ acoplamento capacitivo ocorre por meio de campo elétrico, conforme ilustra a Figura 4, onde a diferença de potencial entre o condutor 1 e o condutor 2, e o dielétrico que os separa, cria uma capacitância parasita.

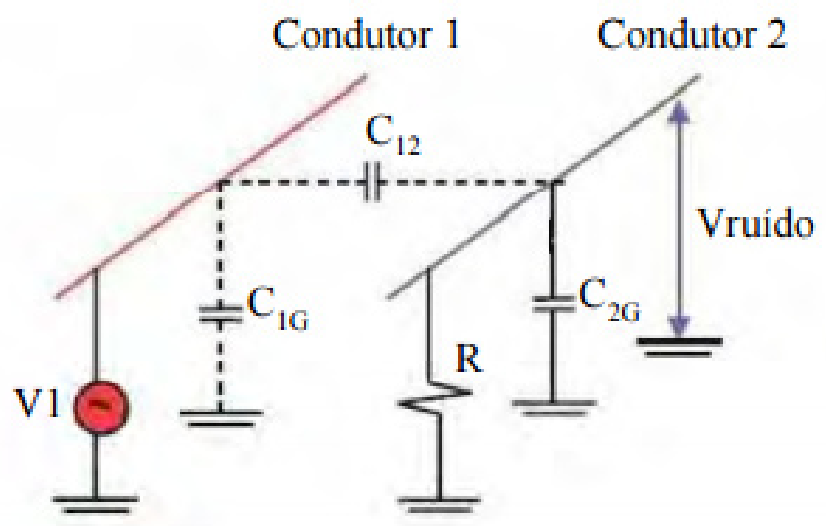

Figura 4. Acoplamento Capacitivo. Fonte: SARTIN, 2010.

\section{Acoplamento por Radiação}

Os acoplamentos radiados ocorrem quando fonte e vítima não possuem ligações físicas. Ocorre por meio de ondas eletromagnéticas propagantes no ar, como acontece em torres de transmissão de sinais de rádio e TV, mostrado na Figura 5.

\section{Acoplamento por Condução}

Neste caso existe ligação física entre fonte e vítima. O acoplamento ocorre por meio de uma impedância comum ou pela própria fonte de alimentação. A Figura 6 ilustra um exemplo onde um motor pode transmitir perturbações tais como sobretensões e harmônicas à rede de alimentação que serão conduzidas até outro equipamento alimentado pela mesma rede.

\section{Modos de Circulação de Correntes}

Os acoplamentos podem provocar correntes circulantes em modo comum e em modo diferencial. $\mathrm{O}$ modo comum refere-se a correntes circulantes entre linhas de sinais e o aterramento. Não há diferença de potencial entre condutores e a tensão é provocada pela existência de uma impedância. Já no modo diferencial, a corrente circula da fonte para a carga por um condutor e o retorno é feito por um outro, como fase e neutro.

A Figura 7 ilustra os modos de circulação de correntes, onde $\mathrm{I}_{\mathrm{md}}$ refere-se à corrente em modo diferencial e $\mathrm{I}_{\mathrm{mc}}$ à corrente de modo comum.

Onde:

$\mathrm{V}_{\mathrm{s}}$ - fonte de alimentação;

$\mathrm{Z}_{\mathrm{s}}^{\mathrm{s}}$ - Impedância limitadora de corrente;

$Z_{L}-$ carga;

$\mathrm{V}_{\mathrm{mc}}$ - tensão em modo comum;

$\mathrm{V}^{\mathrm{mc}}{ }_{\mathrm{mc}}$ - tensão parasita adicionada à tensão da fonte;

$\mathrm{I}_{\mathrm{G}}$ - corrente circulante pela malha de aterramento.

\section{Nível e Margem de Compatibilidade}

Durante o projeto de um dispositivo, equipamento ou sistema, define-se um nível limite superior admissível para as perturbações emitidas e um nível limite inferior de imunidade. Esses limites se referem a quanto um equipamento vai interferir e a quanto este equipamento vai ser interferido. Fora desses limites o funcionamento deste dispositivo pode ser perturbado.

O nível de compatibilidade é um nível de referência para garantir a coordenação entre os limites de emissão e de imunidade, já a margem de compatibilidade é a relação entre os limites de emissão e imunidade.

A Figura 8 ilustra os níveis de compatibilidade e margem de compatibilidade de um dispositivo fictício. 


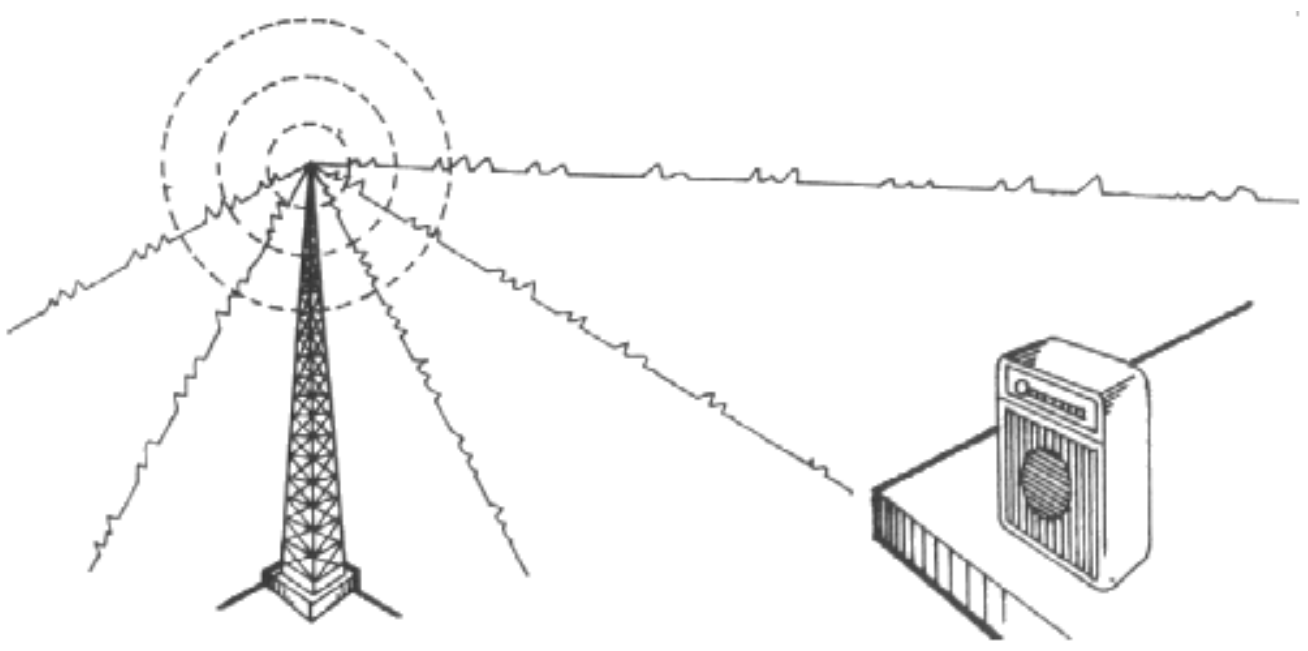

Figura 5. Acoplamento por Radiação. Original disponível em: http://www.ptt-radio.qsl.br/Documentos/ Apostila\%20Ondas\%20e\%20Antenas.pdf

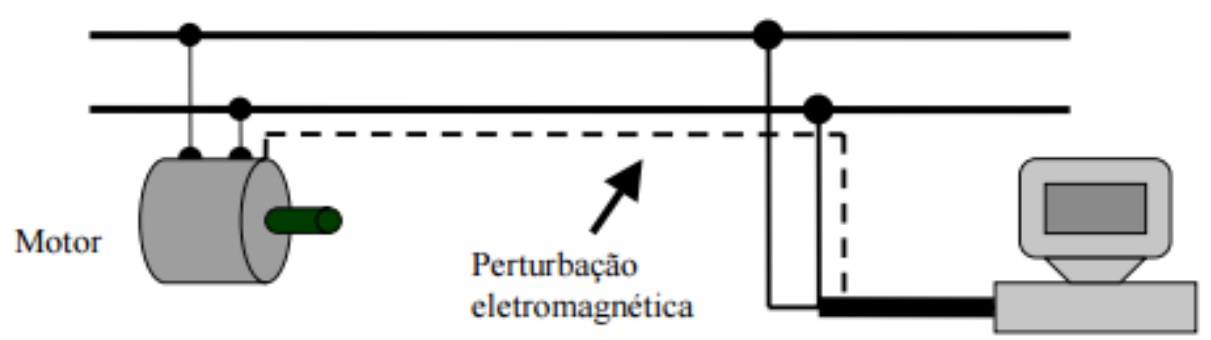

Figura 6. Acoplamento por condução. Fonte: GUIMARÃES, 2008.

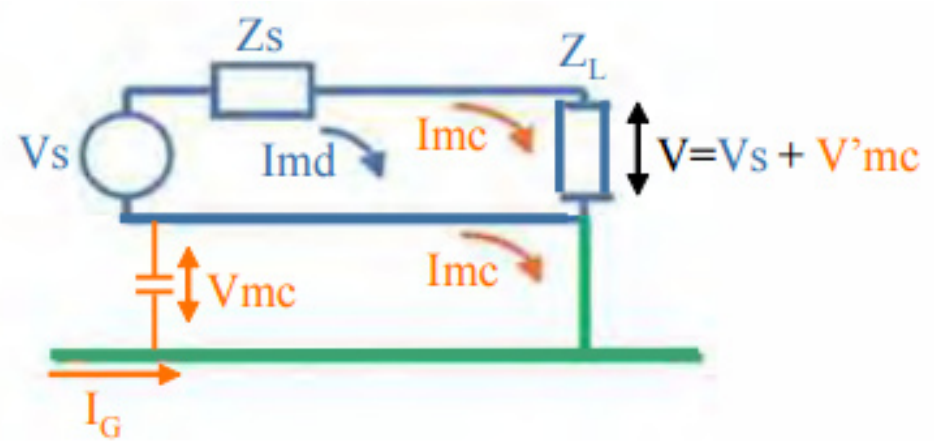

Figura 7. Modos de Circulação de Correntes. Fonte: SARTIN, 2010.

\section{Certificação}

A certificação é o procedimento pelo qual um organismo certificador dá garantia escrita de que um produto ou sistema está em conformidade com requisitos especificados, após serem feitos ensaios exigidos pelas normas pertinentes em um laboratório credenciado para tal finalidade.

No que se refere à EMI/EMC, a diretiva europeia de 1989 criou a marcação CE, que é uma marcação que deve ser ostentada por equipamentos eletroeletrônicos e todos os equipamentos e instalações que contém equipamentos eletroeletrônicos significando a conformidade destes com as exigências da legislação referente à EMI/EMC, garantindo coordenação na operação destes dispositivos de modo que não interfiram nem sejam interferidos. A Figura 9 apresenta a imagem da marcação CE.

Além da marcação $\mathrm{CE}$, existem marcações específicas que são instituídas por órgãos regulamentadores a nível nacional, como a VDE da Alemanha, a CSA do Canadá e a UL nos Estados Unidos. Todas apresentam a característica de declarar 


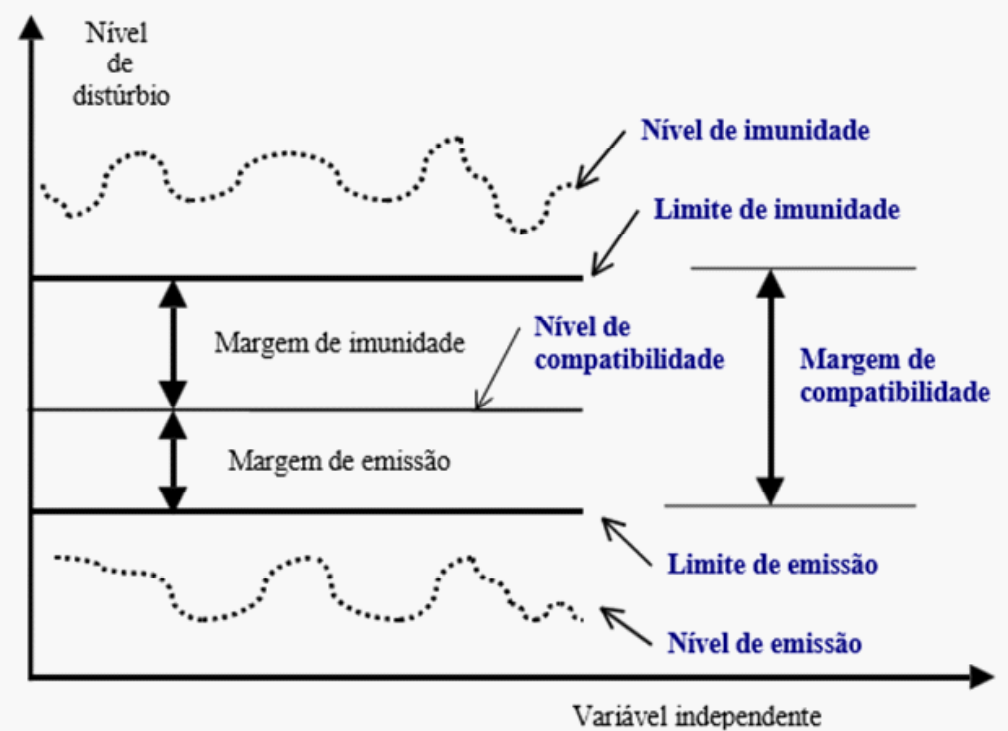

Figura 8. Nível e Margem de Compatibilidade. Fonte: MAGNUS, 2001.
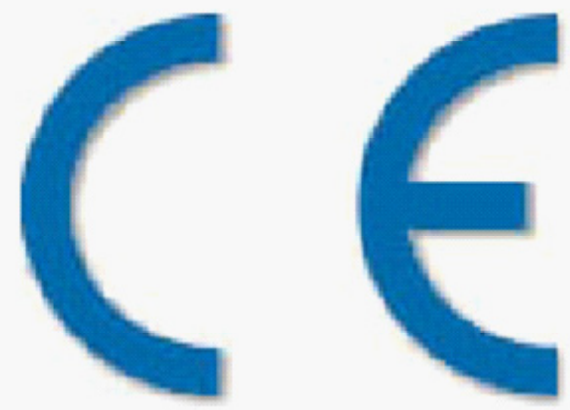

Figura 9. Marcação CE. Fonte: MAGNUS, 2001.

conformidade com legislação pertinente a EMI/EMC. A Figura 10 apresenta um equipamento ostentando tais marcações.

\section{Medidas de EMI}

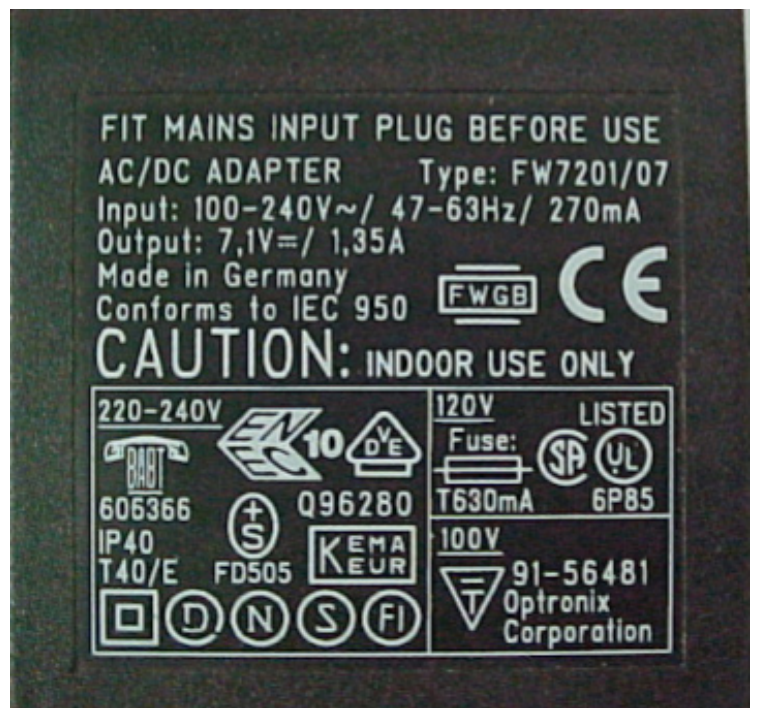

Figura 10. Certificações de um dispositivo. Fonte: MAGNUS, 2001.

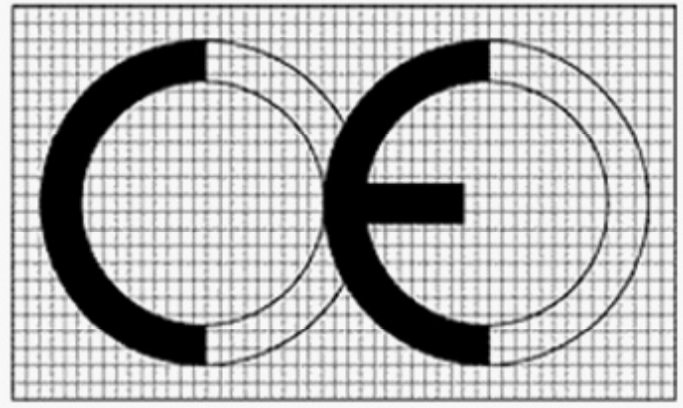

As medidas de EMI são mais confiáveis quando realizadas em sítios de teste em campo aberto. Em caso de impossibilidade, se utilizam câmaras de teste, que são ambientes preparados para que o equipamento seja submetido a perturbações eletromagnéticas de tal modo que seja possível quantificar o nível de EMI e trabalham com o princípio da Gaiola de Faraday, isolando o meio externo do meio interno.

Para a medição de EMI, se utilizam principalmente osciloscópios e analisadores de espectro, uma vez que se deseja medir campos eletromagnéticos e perturbações eletromagnéticas.

As unidades mais comuns em EMC são $\mathrm{V} / \mathrm{m}$ para identificar campos elétricos e $\mathrm{A} / \mathrm{m}$ para campos magnéticos.

\section{Situação Atual e Preocupações}

Nos últimos anos foi possível perceber, segundo a bibliografia especializada, uma preocupação maior em relação ao mau funcionamento de dispositivos oriundos das perturbações eletromagnéticas. No Brasil, é perceptível uma legislação e conformidade inferior em relação aos órgãos regulamentadores ao redor do 
mundo, como o CISPR (Comitê Internacional Especial de Perturbações Radioelétricas) e as estabelecidas pela IEC e a IEEE (Instituto de Engenheiros Eletricistas e Eletrônicos). Por outro lado, o Brasil apresenta maior preocupação quando referido à telecomunicação, possuindo normativos e resoluções normativas específicas para a banda de frequências que abrange este tipo de comunicação. O Brasil ainda ostenta um normativo chamado PRODIST (Procedimentos de Distribuição de Energia Elétrica no Sistema Elétrico Nacional) que estabelece níveis aceitáveis para algumas perturbações, com foco em qualidade de energia.

\section{EMC em Subestações de Energia}

A avaliação do ambiente eletromagnético de subestações é um processo que requer alguns cuidados peculiares, pois se trata de sistemas dinâmicos nos quais correntes e tensões variam constantemente com o tempo e, consequentemente, os campos elétrico e magnético inerentes ao processo.

As subestações podem ser divididas em dois grandes blocos: potência e controle.

A parte de potência é constituída pelas linhas de alta tensão, pelos transformadores e disjuntores de potência e trabalham com altas tensões e altas correntes. No caso do croqui apresentado na Figura 11, se tratando de uma SE de MT, a parte de potência pode ser considerada tanto a entrada de linha em $69 \mathrm{kV}$ quanto nos barramentos de saída de $13,8 \mathrm{kV}$. Já a parte de controle é fornecida pelo TSA (Transformador de Serviços Auxiliares) que permite trabalhar com baixas tensões e baixas correntes, alimentando assim, todo comando e controle das subestações que, em muitos casos, tratase de subestações automatizadas que possuem sistemas supervisórios.

\section{Características físicas que interferem na natureza dos acoplamentos}

Durante o projeto de uma subestação, estima-se toda a demanda que esta subestação deverá fornecer. Com isso, determina-se a quantidade de transformadores de potência, quantidade e tensão nominal de linhas de entrada e linhas de saída, bem como todos os dispositivos pertinentes à instalação. Entretanto, com o aumento do consumo de energia elétrica e consequentemente da demanda que deverá ser suprida pela subestação, são feitas modificações em seu ambiente. Essas modificações consistem em operação de novos equipamentos ou substituição de outros que já estavam em operação. A cada modificação física da subestação, modifica-se também o ambiente eletromagnético pertinente a ela e, para maior confiabilidade, deve-se reavaliar o ambiente eletromagnético toda vez em que algo for modificado. Dentre essas modificações, as mais comuns são:

- Entrada em operação de outros transformadores de potência ou a substituição dos existentes por outros de maior potência, que geralmente dispõem de um comutador de tensão automático sob carga (Load Tap Charger - LTC);

- Novas entradas e saídas de linha, tanto na alta como na baixa tensão;

- Entrada em operação ou ampliação de banco de capacitores e/ou reatores;

- Instalação de reguladores de tensão.

Cada uma dessas alternativas modifica o arranjo da instalação e interfere na natureza e intensidade dos acoplamentos existentes, o que define um novo perfil eletromagnético para a instalação.

\section{Caracterização da EMI em Subestações}

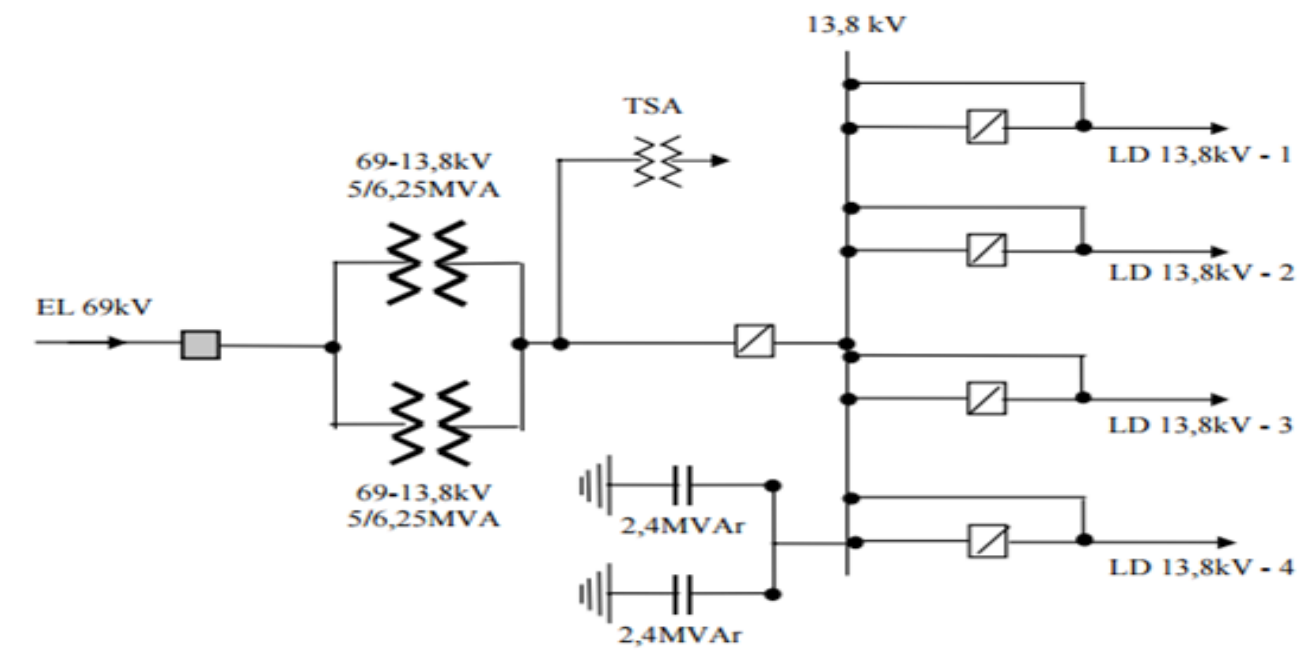

Figura 11. Croqui de uma Subestação MT.

Fonte: SILVEIRA, 2004. 
A EMI é caracterizada em subestações por três razões principais:

- Circuitos eletrônicos com tecnologia analógica ou digital operam com níveis de sinais elétricos muito baixos para processar e transmitir informações;

- Utilizam níveis de tensão e corrente muito altos, de modo que uma pequena porção desta potência, se acoplada não intencionalmente, pode provocar um erro de operação de equipamentos;

- Variações de campos elétricos e magnéticos são capazes de causar acoplamentos indesejáveis entre circuitos. Quanto maior a taxa de variação de tais campos, maior será o acoplamento.

\section{Principais fontes de EMI em Subestações}

Dentre as principais fontes de EMI em subestações, destacam-se:

- Ruídos eletromagnéticos irradiados a partir de arcos elétricos originados em chaveamentos de circuitos de potência. Atingem dezenas de ampères por nanossegundo. Tais irradiações podem atingir circuitos e equipamentos eletrônicos sensíveis, provocando a perda da programação e/ou lógicas de comando ou até mesmo danos físicos;

- Manobras em circuitos de potência com elevado conteúdo de carga indutiva, podendo gerar pulsos de tensão na ordem de $10 \mathrm{kV}$; tais sobretensões podem resultar na tensão de restabelecimento transitória (TRT) do disjuntor manobrado, gerando campos irradiados que podem interferir no funcionamento dos equipamentos eletrônicos sensíveis;

- Correntes de falta fase-terra circulando pela malha de aterramento de força; entre malhas de terras distintas, se não conectadas, ou entre pontos distintos da mesma malha, podem surgir tensões da ordem de dezenas de $\mathrm{kVs}$, com uma faixa de frequências compreendidas entre dezenas de $\mathrm{kHz}$ e até alguns $\mathrm{MHz}$. Nessas circunstâncias, surgem capacitâncias de acoplamento no interior dos equipamentos eletrônicos, mais especificamente entre os pontos aterrados e pertencentes a diferentes malhas de terra (terra de alimentação elétrica e terra de referência de sinal, por exemplo), ou entre pontos aterrados em diferentes locais da mesma malha, gerando a destruição de placas eletrônicas;

- Abertura de disjuntores ou contatores perante a ocorrência de faltas, podendo gerar ruídos eletromagnéticos irradiados, decorrentes do surgimento de arcos elétricos da ordem de uma dezena de $\mathrm{kV}$, com uma faixa de frequências compreendidas geralmente entre $10 \mathrm{kHz}$ e algumas dezenas de $\mathrm{MHz}$;

- Funcionamento de intercomunicadores, que podem gerar campos com intensidade de até $10 \mathrm{~V} / \mathrm{m}$ a 1 metro de distância, a frequências de até algumas centenas de $\mathrm{MHz}$

\section{Controle/Prevenção de EMI em Subestações}

Citadas as principais fontes de EMI, se caracterizam então as melhores formas de mitigar os problemas encontrados bem como melhorar a instalação como um todo. Para tal, recomenda-se a utilização dos seguintes critérios:

a) Melhoria/adequação dos sistemas de aterramento

É recomendada a utilização de 2 malhas de terra, uma malha de aterramento geral, de segurança e uma malha de aterramento de referência para os sinais, obrigatoriamente conectadas a fim de escoar as correntes de alta e baixa frequências eventualmente introduzidas em cada subsistema de aterramento, além de prover a desejável equalização dos potenciais.

b) Separação entre fontes de ruído e receptores

Uma vez da impossibilidade de se eliminar as fontes de interferências eletromagnéticas, recomenda-se afastar os equipamentos geradores de intensos campos eletromagnéticos (fontes) dos equipamentos muito suscetíveis a tais campos (receptores). Quanto maior a distância física entre equipamentos eletrônicos sensíveis e as potenciais fontes geradores de ruídos, menor será a interferência, principalmente de ondas eletromagnéticas irradiadas.

c) Utilização de blindagens

Em EMC utilizam-se basicamente dois tipos de blindagens: metálicas e condutivas.

As blindagens metálicas são indicadas quando se deseja atenuar campos magnéticos. Estas blindagens possibilitam que o fluxo magnético resultante em seu interior seja menor que o fluxo no material utilizado para a blindagem. Para tal, a atenuação proporcionada por essa blindagem é diretamente proporcional à permeabilidade magnética do material utilizado na blindagem.

Já as blindagens condutivas, visam atenuar os campos elétricos e atuam através do princípio de que o fluxo magnético incidente provoca a circulação de correntes (corrente de Foucault) que se opõem ao fluxo que as gerou (Lei de Lenz). A atenuação proporcionada por esta blindagem é diretamente proporcionam à condutividade elétrica do material utilizado na blindagem.

d) Separação das cablagens 
É recomendado que se mantenham as cablagens organizadas por categoria, potência e sinais separadamente, de maneira a evitar a proximidade destes uma vez que os cabos de potência, com altas tensões e altas correntes, podem causar acoplamentos indesejáveis de tensões nas cablagens de sinais, podendo acionar algum equipamento de maneira equivocada. Além disso, as normas MIL-STD-461 e MIL-STD462 apresentam ensaios acerca de bandejas metálicas, concluindo que a utilização de bandejas de alumínio, além de oferecerem boa resistência mecânica, é melhor que o aço para a atenuação de campos magnéticos.

e) Supressão de surtos conduzidos

Trata-se da proteção contra sobretensões. Objetiva a atenuação de ruídos conduzidos entre diferentes partes de um sistema, através de filtros ou supressores de surto, tais como diodos zener, varistores e centelhadores a gás. São colocados nos circuitos de alimentação CA dos equipamentos bem como nos estágios de entrada e saída de circuitos de comunicação de dados.

\section{f) Proteção contra descargas atmosféricas}

As descargas atmosféricas constituem uma intensa descarga eletrostática com altos valores de amplitude de tensão e corrente em um curto espaço de tempo, em altas frequências. A proteção contra descargas atmosféricas permite anular o efeito de acoplamentos não intencionais pelo escoamento desta descarga para a malha de terra. Outra vez ressalta-se a importância de utilizar uma boa malha de aterramento, sendo recomendada uma malha exclusiva para o sistema de proteção contra descargas atmosféricas. É importante ressaltar também que as malhas de aterramento devem possuir a menor indutância possível, uma vez que a reatância indutiva é diretamente proporcional à frequência e as descargas atmosféricas possuem elevada frequência, a reatância indutiva será muito alta, fazendo com que a descarga procure um caminho alternativo de menor resistência resultando, em muitas vezes, na destruição de equipamentos eletrônicos.

\section{g) Uso de transformadores de isolação}

São transformadores com relação de transformação 1:1. São utilizados principalmente para alimentar equipamentos eletrônicos sensíveis, uma vez que, como não existe ligação elétrica entre primário e secundário, é possível atenuar as perturbações conduzidas oriundas do primário tais como harmônicas e sobretensões.

De maneira similar, pode-se utilizar optoacopladores, que utilizam o mesmo princípio de isolamento elétrico entre primário e secundário, sendo conectados por meio de sinal luminoso.

h) Utilização de fibras ópticas

As fibras ópticas são recomendadas quando existe a necessidade de circular cablagem pelos pátios de manobras das subestações, uma vez que estas são insensíveis a perturbações eletromagnéticas, constituindo uma boa alternativa para a transmissão de informações dos sistemas de controle. Economicamente as fibras estão mais baratas e representam boa solução para este caso. Em que pesem as vantagens, as fibras ópticas apresentam pouca flexibilidade e recomenda-se não utilizar reforço metálico pois, além de reduzir ainda mais a flexibilidade, o reforço metálico pode atuar como antena e transmitir perturbações conduzidas.

\section{i) Tecnologia emergente: Concreto Condutivo}

Já é muito utilizado na América do Norte, principalmente para derretimento de neve. É um material obtido com o uso de cimento agregado a outros insumos condutivos tais como fibra de carbono, grafite e "coque-brezze" (partículas de carvão de reduzida granulometria), de modo a se perfazer uma malha condutora contínua. O princípio de funcionamento é através da aplicação de baixas tensões em sua estrutura, que gerarão correntes que percorrerão toda a estrutura e aquecerão a malha. Estudos apontam que esta tecnologia proporciona atenuações de campo magnético na ordem de 10 a $36 \mathrm{~dB}$ sendo mais eficaz que as chapas de aço para frequências a partir de $25 \mathrm{kHz}$.

\section{Conclusão}

O presente artigo teve por objetivo apresentar os conceitos fundamentais sobre EMI/EMC e suas causas e efeitos nos sistemas elétricos de potência. Avaliar o ambiente eletromagnético no qual um sistema está inserido é o primeiro passo a ser dado para garantir harmonia na operação de sistemas geradores de intensos campos eletromagnéticos e de equipamentos muito suscetíveis a estas perturbações.

A avaliação dos acoplamentos eletromagnéticos em subestações constitui uma informação relevante na caracterização do ambiente eletromagnético da instalação que, após identificados os problemas e tomadas as devidas medidas, proporcionarão funcionamento harmônico entre sistemas de potência e controle. 


\section{Referências}

Beltrame, F. (2010). Seminário de Eletrônica de Potência (SEPOC). Interferência Eletromagnética. Universidade Federal de Santa Maria.

Guimarães, J. V. (2008). Ensaios de proficiência em compatibilidade eletromagnética: programa exploratório de medidas de emissão radiada. Dissertação de mestrado em engenharia elétrica. Instituto Militar de Engenharia.

Magnus, E. F. (2001). Desenvolvimento de uma ferramenta para ensaios de EMI conduzida de baixo custo.Dissertação de mestrado em engenharia elétrica. Pontifícia Universidade Católica do Rio Grande do Sul.

Sartin, A. C. P. (2010). Avaliação da suscetibilidade eletromagnética em cabos metálicos dos sistemas de supervisão, proteção, comunicação $e$ controle de subestações de alta tensão. Dissertação de mestrado em engenharia elétrica. Universidade Estadual Paulista.

Silveira, C. A. (2004). Uma contribuição à avaliação de acoplamentos eletromagnéticos em subestações do sistema elétrico. Teste de doutorado em engenharia elétrica. Universidade Federal de Pernambuco. 